\title{
Sobre o desafio do currículo escolar na contemporaneidade
}

\author{
VALDENIZA LOPES DA BARRA* \\ Universidade Federal de Goiás (UFG) - Brasil \\ Recibido el 28-06-21; evaluado el 11-07-21; \\ aceptado el 06-08-21
}

\section{RESUMO}

O texto trata o currículo escolar em três momentos. Primeiramente promove interlocução com estudiosos brasileiros que discutem explicitamente o currículo escolar na realidade brasileira. Em seguida identifica algumas raízes da conjuntura que induz ao deslocamento da lógica que preside o currículo, antes a especificidade do conhecimento e, a partir de certo momento, investido das diversas questóes socioculturais contemporâneas. Para tal, se vale de perspectivas teóricas que tematizam o paradigma da historicidade, a pós-modernidade e o "amplo tempo" presente. Assim, indica a emergência e os desafios de temas apagados, rememorados, reformulados, inaugurados (conflitos étnico-raciais, meio ambiente, sexualidade, dentre outros), instituindo novas relaçóes entre passado, presente e futuro. Por fim, aponta sinais de deslocamento do currículo escolar em dois documentos estruturais e reguladores do tema no Brasil contemporâneo.

Palavras-chave: currículo, escola, contemporaneidade.

\section{Sobre el cambio del currículo escolar en la contemporaneidad}

\section{RESUMEN}

En este texto se analiza el currículo escolar en tres momentos. Inicialmente, promueve una interlocución con estudiosos brasileños que discuten explícitamente el currículo escolar en la realidad brasileña. En seguida, identifica algunas raíces de la coyuntura que induce a un cambio de rumbo de la lógica que preside el currículo, ante la especificidad del conocimiento y, desde cierto momento, tratando de las diversas cuestiones culturales contemporáneas. Para eso, se utilizan perspectivas teóricas que tematizan el paradigma de la historicidad, la posmodernidad y el

\footnotetext{
* Doutorado em Educaçấo: História, Política, Sociedade junto à Pontifícia Universidade Católica de São Paulo (Brasil). Professora associada, com atuação na graduação e pós-graduação da Faculdade de Educação da Universidade Federal de Goiás (UFG) - Brasil. Temas de interesse: formaçăo de professores, estágio, cotidiano, escola. https://orcid.org/0000-0001-5153-4860. Correio eletrônico: valdenizamaria@ufg.br
} 
«amplio tiempo» presente. Así, indica a la emergencia y a los desafíos de temas borrados, rememorados, reformulados, inaugurados (conflictos étnico-raciales, medio ambiente, sexualidad y otros), instituyendo nuevas relaciones entre pasado, presente y futuro. Al fin, muestra el cambio del currículo escolar en dos documentos estructurales y reguladores del tema en el Brasil contemporáneo.

Palabras clave: currículo, escuela, contemporaneidad.

\section{The leap of the school curriculum in contemporaneity}

\section{Abstract}

The text analyses the school curriculum in three moments. First, it promotes dialogue with Brazilian scholars who openly discuss the current school curriculum in Brazilian reality. Then, it identifies some roots of the situation that induces the leap in the logic that guides the curriculum, rather than the specificity of knowledge and, from a certain point, provided in various contemporary sociocultural issues. For this purpose, the article draws on theoretical perspectives that thematize the paradigm of historicity, post-modernity, and the present "long time". This analysis indicates the emergence and challenges of themes that have been erased, remembered, reformulated, and inaugurated (ethnic/racial conflicts, environment, sexuality, among others), establishing new relationships between past, present, and future. Finally, it shows the leap in the school curriculum in two structural documents that regulate the theme in contemporary Brazil.

Keywords: curriculum, school, contemporaneity.

\section{INTRODUCCIÓN}

\subsection{Começo de conversa: apontamentos iniciais acerca do debate sobre o currículo escolar}

A par do entendimento de que a escola seja uma instituição fundamental da sociedade, se verifica que o mesmo não acontece, quando o assunto é o que ela - a escola - deve ensinar, sendo esta uma problemática comum a realidades distintas. Ciosos deste debate no plano internacional, Libâneo e Silva (2020) demonstram o quanto esta questão pode e deve ser pensada em associação com as finalidades da educaçáo escolar, sobre as quais duelariam frentes divergentes como "instruçáo ou socialização, de abertura ou controle, de educação geral ou qualificação profissional, de escolarização ou atendimento à diversidade sociocultural, de formação de valores conservadores individualistas ou valores coletivos de justiça, de solidariedade, autonomia” (2020, p. 819). 
Como gerir a condição pendular de uma instituição sobre a qual pesa o fato de ser considerada necessária para a grandíssima maioria da sociedade e, a um só tempo, também ser tomada como a "panaceia para os problemas da sociedade (Libâneo e Silva, 2020, p. 818)"? O dissenso sobre a questão é protagonizado pelos meios político, acadêmico, sindical, empresarial, como indica Libâneo (2019, p. 56). Mas não só. Pesquisa canadense revela que inexiste entendimento entre professores, formadores de professores, futuros professores e público em geral, quando os temas são autonomia, responsabilidade, cidadania, preparaçáo para o trabalho, educaçáo intercultural, educação para a sustentabilidade, etc. (Lenoir, 2013 apud Libâneo, 2019), p. 57).

As tensôes envoltas ao currículo escolar são adensadas nas sociedades contemporâneas, caracterizadas pela complexidade advinda de múltiplos fatores dentre os quais, a globalização, o neoliberalismo, a revolução informacional, a marcante desigualdade econômica, os conflitos étnico-raciais, as catástrofes ambientais, o recrudescimento de forças políticas conservadoras e, com efeito, o modo estes eventos pressionam as políticas educacionais e os respectivos desenhos curriculares. Para José Carlos Libâneo, as características inerentes às propostas curriculares podem ser pensadas a partir de quatro perspectivas distintas, tal como se pode ler no quadro a seguir.

Quadro 1. Perspectivas de currículo.

\begin{tabular}{|c|c|c|c|}
\hline $\begin{array}{l}\text { Pedagogia tradi- } \\
\text { cional e currículo } \\
\text { tradicional }\end{array}$ & $\begin{array}{l}\text { Visão neolibe- } \\
\text { ral e currículo } \\
\text { de resultados }\end{array}$ & $\begin{array}{l}\text { Visão sociológica- } \\
\text { intercultural e currícu- } \\
\text { lo tradicional }\end{array}$ & $\begin{array}{c}\text { Visão dialética histórico- } \\
\text { cultural e currículo de } \\
\text { formação cultural e } \\
\text { científica }\end{array}$ \\
\hline $\begin{array}{l}\text { Preservação de } \\
\text { valores morais, } \\
\text { formação moral } \\
\text { e cívica, ensino } \\
\text { verbal, rigor } \\
\text { disciplinar, } \\
\text { hierarquia e } \\
\text { autoridade na } \\
\text { relação professor } \\
\text { e aluno. }\end{array}$ & $\begin{array}{l}\text { Defesa de } \\
\text { competências e } \\
\text { habilidades. } \\
\text { A aula é o } \\
\text { espaço em que } \\
\text { professores } \\
\text { preparam os } \\
\text { alunos para } \\
\text { responderem a } \\
\text { testes. }\end{array}$ & $\begin{array}{l}\text { Foco maior na prática } \\
\text { social de contextos } \\
\text { socioculturais } \\
\text { imediatos (diversidade } \\
\text { social e cultural, } \\
\text { compartilhamento de } \\
\text { diferentes valores e } \\
\text { solidariedade). } \\
\text { Foco menor nos } \\
\text { saberes sistematizados. }\end{array}$ & $\begin{array}{l}\text { Currículo de formação } \\
\text { cultural e científica } \\
\text { articulado com a } \\
\text { diversidade sociocultural. } \\
\text { A escola promove } \\
\text { justiça social (inclusáo e } \\
\text { democratização) quando } \\
\text { assegura aos alunos os } \\
\text { saberes historicamente } \\
\text { produzidos. }\end{array}$ \\
\hline
\end{tabular}

Fonte: Elaborado pela autora a partir de Libâneo (2019, pp. 69-76).

Ao optar pela visão apresentada na quarta coluna, o autor se revela partidário de uma concepção de currículo atenta aos conhecimentos científicos e engajada com as questôes socioculturais, o que tornaria a escola uma instituição promotora da justiça social. A pergunta passa a ser quais seriam as credenciais 
para os professores operarem em tal perspectiva de currículo, quando se sabe que a condição de trabalho desses profissionais passa por processos crescentes de precarização e desvalorização. Ao mesmo tempo em que deles se espera que compreendam "o papel da escola no mundo de hoje, as relaçóes entre os processos", que saibam "responder à situação de desigualdade e à diversidade cultural", que compreendam "como as novas tecnologias podem constituir um importante instrumento para democratizar o acesso ao conhecimento", que precisam refletir valores difundidos e a se difundir, pensar identidades. (Moreira, 2006, p. 11). Endossa esta posição, Garcia (2006, p. 12), para quem "só pode fazer tudo isso [professor] se tiver uma cultura geral ampla". Residiria aí a chave. A formação ampla garantiria ao professor a condição de quem conseguiria realizar uma "tradução permanente" daquilo que deve ser ensinado em face de cada nova situação ou novo desafio.

Esta não é uma operação simples. Em outro ponto do diálogo entre Moreira e Garcia (2006), o primeiro admite que tratar o currículo escolar não é uma tarefa fácil pois "a ideia de currículo se ampliou tanto que não sei mais o que ela significa” (p. 23). Moreira provoca Regina Garcia a falar do seu entendimento sobre currículo stricto sensu e currículo lato sensu. Ao que ela responde, o stricto sensu traduz a "visão perigosa do especialista", restrita apenas à escola e à sala de aula. Por outro lado, o currículo lato sensu abre demais, sai da escola para o seu entorno, vai ao shopping center, à cidade, à sociedade e ao mundo onde a escola está, donde "surge o perigo de perder a questão central que seria a questão do currículo na escola" (Garcia, 2006, p. 23.-24). Minimamente, o que se deduz é que, em se tratando do currículo escolar na contemporaneidade, não há como fugir do perigo, há problemas a serem enfrentados em qualquer caminho que se decida percorrer.

No exercício de reflexão sobre a problemática não faltam estudiosos comprometidos em desvelar suas nuanças do currículo escolar na contemporaneidade. Para Nóvoa, o principal desafio da escola é:

Decidir o que é essencial ensinar aos alunos e garantir que as disciplinas elementares náo sejam prejudicadas pela avalanche de conteúdos que são propostos atualmente. Hoje, a equipe docente se ocupa da Educação Ambiental, alimentar e comportamental e com programas de prevenção à aids, acidentes de trânsito e violência sexual. Todos muito importantes, mas que não sáo responsabilidade da escola. Ao tentar colocar tudo no mesmo pote, falta espaço para o básico (Rodrigues, 2010)

O autor mencionado avalia que, embora seja difícil definir o essencial no currículo de escolas em contextos de muita desigualdade econômica, como é 
o caso brasileiro, onde a pauta de conhecimento revela a tendência de subordinação à pauta social, é possível distinguir no currículo aquilo "que une" e aquilo "que liberta", numa referência a Olivier Reboul (1925-1992), filósofo francês. Diante disso, Nóvoa entende que a Língua, as Artes Plásticas, a Música e a História portam conteúdos que integram o homem à cultura, enquanto a Matemática, as Ciências e a Filosofia libertariam o homem ao promoverem tanto a aquisição do conhecimento, como o despertar do espírito científico e a capacidade de julgamento próprio. Não se questiona a necessidade que estudantes tenham de receber noções de higiene, alimentação, meio ambiente, violência sexual, dentre outros, mas estas não devem ser responsabilidade da escola, tendo em vista que a sociedade atual possui instituiçôes e profissionais com conhecimento nessas áreas que podem prover essa formação (museus, associações, estudiosos, institutos, fundações), além de serem mais preparados para tratar de certos temas do que um professor. Indicando assim que é preciso distinguir as atribuiçôes da escola e as atribuiçôes da sociedade na formação humana.

A escola brasileira experimenta, desde Anísio Teixeira, iniciativas que, sob o pretexto de atenuar problemas sociais, consegue a façanha de, no mesmo movimento que promove a ampliação da jornada escolar, também comprime a pauta do ensino do conhecimento sistematizado, desideratum genuíno da escola. O que se pode conferir em artigo publicado em 2014, quando se indicava que na raiz do processo de escolarização das grandes massas da população brasileira na segunda metade do século XX, também havia a intensificaçáo e o favorecimento da perda da identidade cultural e pedagógica da escola brasileira, pela via da política de ampliação do tempo escolar. (Barra, 2014, pp. 116-117). Tal percepção dialoga com numerosos estudiosos, como Dalben (2011), a quem interessa pensar as particularidades da oposição e possibilidades de superação entre a escola do conhecimento e da aprendizagem versus a escola de acolhimento. $\mathrm{Na}$ mesma linha irmanam reflexôes como as de Libâneo (2011, p. 86), que reconhece em tais políticas o desapreço à referência básica da ação educativa escolar: a formação humana mediante as práticas de ensino e aprendizagem, conduzindo-se à diluição da especificidade escolar. Também se alinham a este pensamento, Paro et al. (1988, pp. 198-202), que reconhecem a dimensão assistencial como "uma das mais caras aos projetos recentes de expansão do tempo diário de atendimento da criança pelo Estado" em desfavor da escola cuja função precípua é a "divulgação do saber sistematizado". Em posição paralela e complementar, Marília Gouvêa de Miranda (2005), ao estudar a organização do ensino em ciclos, adverte sobre a mudança nos princípios que regem a organização dos 
tempos e espaços da escola pública, tendo em vista que "a escola constituída no princípio do conhecimento estaria dando lugar a uma escola orientada pelo princípio da socialidade" (p. 639).

\section{Desarrollo}

\subsection{A lógica que preside a escola na contemporaneidade: da especificidade à generalizaçáo do currículo}

Nesta seção se pretende buscar raízes que possuam alguma força de explicação que ajude na compreensão acerca do ponto de inflexão entre o currículo pautado pelo conhecimento e o currículo estendido às questóes socioculturais.

\subsubsection{A contemporaneidade e o paradigma da historicidade}

O desmoronamento do paradigma estruturalista cede vez à emersão de uma organização intelectual na qual o tema da estrutura foi substituído pela historicidade. Segundo Dosse (2004), o estruturalismo consistiu-se num paradigma crítico que vigorou entre 1950 a 1975 e reunia uma disciplina-modelo, a linguística, duas disciplinas rainhas, a sociologia e a etnologia, e duas doutrinas de referência, o marxismo e a psicanálise. Esta corrente de pensamento tinha a "ambição de apreender a realidade de maneira objetiva e científica", e primava-se pela descentralização e zelava da capacidade de "expropriar o sujeito" (p. 397). A partir dos anos 1980 este paradigma cedeu vez a uma organização intelectual que reabilitava a parte "explícita e refletida da ação" (p. 397), de um enveredar ao rumo da consciência dos atores. E é entáo que a identidade histórica passa a ser colocada no centro das interrogaçôes. Eis o paradigma da historicidade.

Pensar o paradigma da historicidade favorece entender deslocamentos relevantes que se operam na contemporaneidade. Primeiramente em relação ao conhecimento e ao sujeito, já que anteriormente as competências das pessoas comuns eram tomadas como ilusão ideológica. A partir de então se passava a levar a sério aquilo que é dito pelos próprios atores, pois se passa a reconhecer que estes teriam competência para analisar a própria situação, a um só tempo em que o conhecimento ordinário, o sentido comum, passariam também a serem reconhecidos como lócus de saberes (Dosse, 2006).

O mundo da vida e os diversos procedimentos de subjetivaçáo e de socialização encontram-se nas bases de um trabalho que só poderia ir de encontro às ciências humanas, quando esta se interroga sobre o sentido que se deve dar à prática social. (...) O conceito não se opôe mais ao vivido para desqualificá-lo, 
e a busca de sentido realiza-se a partir de "meditaçóes imperfeitas", numa dialética inacabada", sempre aberta para sentido novo. (...) O sujeito encontra-se sempre implicado em algo devido à sua relação com o mundo. (Dosse, 2006, pp. 399-400).

Outra tendência observada por Dosse é a problematização da dissociação entre história e memória, instituindo uma descontinuidade que reveste a relação com o passado de novos sentidos. Para sublinhar os efeitos desta postura, Dosse se apoia em Nora, que indica haver menos preocupação com açôes memorizadas e mais com os vestígios que elas deixam, menos preocupação com o passado como ele passou, e mais com os seus reempregos sucessivos, menos preocupaçáo com a tradição e mais com o modo como ela se constituiu e se transmitiu (2006, pp. 405-406). Daí entra em cena o paradoxo do esquecimento na relação com a tomada de consciência. O esquecimento é necessário como forma de dizer ao passado que este já náo pode reger o presente, mas também o esquecimento pode ter como efeito a volta do passado em aspectos que assombram o presente, originando violências aparentemente incompreensíveis (Dosse, 2006, pp. 406-407). $\mathrm{O}$ tratamento destinado ao modo como a memória rompe a divisa e instaura novas relaçôes entre passado, presente e futuro, também faculta pensar que o avivamento de apagamentos pretensamente perpetrados pela racionalidade até então triunfante e homogeneizante de sociedades capitalistas exige uma "ética de responsabilidade para o presente (Dosse, 2006, p. 407)", e esta deve-se ater sobre os "múltiplos possíveis" da duração histórica presente como forma de "pensar o mundo de amanhâ".

\subsubsection{A contemporaneidade e as mini racionalidades (pós-modernas)}

Souza Santos (2003) avalia os desafios contemporâneos decorrentes de uma sociedade capitalista que, a despeito de sofrer profundas transformaçôes, não rompe com a lógica do capital, o que a conduz ao paradoxo de, a um só tempo em que provoca o esgotamento do projeto da modernidade, também dele se alimenta, perpetuando-se neste mesmo esgotamento. Isso produz um vazio, não é ruptura nem continuidade, mas requer que imaginemos o futuro e criemos as necessidades que poderão tornar o presente "diferente e melhor". (Souza Santos, 2003, p. 102). Para este autor, o que emerge desta situação é o paradigma da pós-modernidade que ele se propóe tratar a partir de seis "guióes", conforme sintetiza o quadro 2. 
Quadro 2. Mini racionalidades e resistência na pós-modernidade (Souza Santos, 2003).

\begin{tabular}{|c|c|}
\hline Guióes & Alguns aspectos \\
\hline $\begin{array}{l}1^{\circ} \text { O saber e a ignorância } \\
\text { Näo toque. Isto é humano. } \\
\text { É mais importante estar próximo } \\
\text { do que ser real } \\
\text { Afirmar sem ser cúmplice, criticar } \\
\text { sem desertar. }\end{array}$ & $\begin{array}{l}\text { "A ignorância se tornou cada vez menos desculpável e } \\
\text { algum conhecimento é cada vez mais intolerável". } \\
\text { Alerta sobre o avanço da mercadorização do corpo } \\
\text { humano. } \\
\text { "O real e o próximo são antagônicos", privilegia-se o } \\
\text { próximo em detrimento do real. } \\
\text { Busca da "genuinidade" nos depósitos de } \\
\text { manipulação e dominação. }\end{array}$ \\
\hline $2^{\circ} O$ desejável e o possivel & $\begin{array}{l}\text { Consciência do excesso: aprende-se a não desejar tudo } \\
\text { o que é possível porque é possível. Consciência do } \\
\text { déficit: aprende-se a desejar o impossível. }\end{array}$ \\
\hline $3^{\circ} O$ interesse e a capacidade & $\begin{array}{l}\text { Mantém-se o interesse em superar o capitalismo, mas } \\
\text { parece náo haver capacidade para tal. A vista se volta } \\
\text { para questóes ecológicas, guerra nuclear, diferenças } \\
\text { sexual e racial. }\end{array}$ \\
\hline $\begin{array}{l}4^{\circ} O \text { alto e o baixo ou o solista e } \\
\text { o coro }\end{array}$ & $\begin{array}{l}\text { Hierarquias: aprofundamento de um lado, } \\
\text { trivialização de outro, deslegitimação de ambos os } \\
\text { lados. }\end{array}$ \\
\hline $5^{\circ}$ As pessoas e as coisas & $\begin{array}{l}\text { Nos domesticamos com as coisas e nos estranhamos } \\
\text { com as pessoas }\end{array}$ \\
\hline $\begin{array}{l}6^{\circ} \text { As minis racionalidades não } \\
\text { são racionalidades mínimas }\end{array}$ & $\begin{array}{l}\text { "Quanto mais global for o problema, mais locais e } \\
\text { mais multiplamente locais devem ser as soluçóes." }\end{array}$ \\
\hline
\end{tabular}

Fonte: Elaborado pela autora a partir de Souza Santos (2003, pp. 102-111).

O autor em questão entende que o cenário contemporâneo, a par de revelar desafios de grande monta, também revela possibilidades ou "mini racionalidades" que devem calçar as açôes do presente. É otimista. Parece mesmo tomado "pela mão de Alice", como o próprio anuncia de antemão no título do livro. Impossível não admitir que as minis racionalidades intentadas por Souza Santos (2003) são portadoras de pautas que convergem com as tendências que dirigem e tensionam os debates sobre o currículo escolar na contemporaneidade.

\subsubsection{A contemporaneidade como palco do "amplo tempo" presente}

Uma terceira perspectiva para compor o exercício de pensar a conjuntura da qual emergem os desafios do currículo escolar na contemporaneidade é a ideia proposta por Gumbrecht (2010) de "tempo presente", em que o autor transita entre a crítica literária, a filosofia e a história. Entende que a atualidade padece 
de um ceticismo tal que "rejeitamos qualquer prognóstico para o futuro" (p. 149), razão pela qual "preferimos fazer cálculos de risco, isto é, preferimos imaginar o quanto nos custaria se náo ocorressem determinadas situaçôes que esperamos que sucedam". Estaríamos a romper uma assimetria na qual o passado era tratado como "espaço de experiências", fonte da qual se pinçavam leis de mudança histórica que favoreciam a produção de cenários para o futuro, este que correspondia a um "horizonte de expectativas". Instaura-se neste diapasão "o presente que se torna cada vez mais amplo", visto que sedia o passado que náo quer passar (museus, cultura de nostalgia, moda retrô, narrativa de que não se vive sem memória, tecnologias que atualizam o passado diariamente e impedem o esquecimento) e o "inacessível futuro 'novo"”.

O "tempo amplo" exige que a prática de ensino coloque a "complexidade em cena", pois "é preciso chamar a atenção dos alunos para fenômenos e problemas complexos, mais do que prescrever modos de compreender certos problemas" (p.158), romper a ideia de que a leitura se reduz à atribuição de sentido, mas se trata de "um movimento interminável (...) alegre e doloroso entre perder e voltar a ganhar controle intelectual e orientação" (p. 159). Enquanto a sala de aula corresponderia a um espaço no qual se deve estar "aberto aos outros" sem cair na armadilha de ficar absorvido por instituiçóes e posiçôes", a "presença real" não pode ser suplantada pelas "telas de computador deploravelmente higiênicas", sobre o que adverte: "o futuro da presença necessita do nosso compromisso presente". Seguindo as pistas deste autor, Bárbara Novaes sumariza para as oscilaçóes que povoariam o "amplo presente": 1) a necessidade de preservar o planeta, a vida e o ceticismo que induz a pensar na impossibilidade de se chegar ao "realmente real"; 2) a demanda pela experimentação do corpo (sexualidade, esporte radical) e a exigência que o Estado cuide dos corpos velhos e doentes; 3) substituição progressiva do poder militar pela diplomacia e ações humanitárias, ao mesmo tempo em que se afirma o próprio corpo pela dor (cirurgias plásticas, suicídio, tatuagem, distúrbios alimentares); 4) de um lado a mídia eletrônica a solapar o ato de pensar que cede vez ao "passar a bola" e de outro lado, o "pensamento como práxis da dimensão da existência”, solitário e demorado, proposto como a via para a ação revolucionária (Novaes, 2017, p. 359).

Afora especificidades de um ou outro autor tratado nesta seçáo (Dosse, 2006; Souza Santos, 2003; Gumbrecht, 2010), interessa destacar o quanto suas perspectivas qualificam a compreensão daquilo que constitui a contemporaneidade, dimensão espaço-temporal na qual se inscreve o desafio de pensar o currículo escolar. Enquanto o paradigma da historicidade (Dosse, 2006), para o qual o que está em jogo é a tomada de consciência e, portanto, interessa o sujeito, como age, como se implica com o mundo. Também este paradigma 
aponta para o presente como dimensão espaço-temporal suscetível à flutuação da memória, que é potencialmente atualizadora de acontecimentos traumáticos do passado, e ao fazê-lo, são desencadeados processos que plantam incertezas e, portanto, impelem pela necessária responsabilidade ética com a condução do presente. Por sua vez, tomado Souza Santos (2003), se revela menos pessimista e explica a contemporaneidade sob o prisma da pós-modernidade da qual extrai pequenas racionalidades que podem ser roteiros para entender, se posicionar e enfrentar, na atualidade, o legado da racionalidade moderna que pretendeu homogeneizar, universalizando a fragmentação do conhecimento e do indivíduo. E enfim, Gumbrecht, este que nos ajuda a entender o processo de inchação do presente, premido pela nostalgia do passado e pela angústia em relação ao futuro, o que o aproxima, ainda que por vias distintas, de François Dosse (2006) e Souza Santos (2003).

O protagonismo de temas como a corporeidade, o meio ambiente, as questôes étnico-raciais é também resultante da percepção de que sendo "impossível” ganhar a guerra contra o capitalismo, seria necessário olhar para outras frentes de combate (Souza Santos, 2003), ainda que estas novas apostas revelem contradiçôes ou "oscilaçôes" (Gumbrecht, 2010), elas também seriam tradutoras de resistências, como indica Souza Santos (2003). Daí valer a pena lembrar Moreira (1997), em texto sob título Currículo, utopia e pós-modernidade, no qual endossava a compreensão de uma "pedagogia radical" que combinasse "elementos teóricos centrais do pós-modernismo com as categorias do discurso progressista” (p. 10). E, por tabela, recuperar Dosse (2006), que ao apontar o paradigma da historicidade, elucida a emersão do sujeito, sua ação, e relação com o mundo, sua "tomada de consciência".

O percurso realizado na seção 2 pretendeu identificar algumas raízes que podem ajudar a entender o deslocamento das questóes do conhecimento para as questóes socioculturais da sociedade contemporânea. Mas, tal como indica Silva (2005), a questão central para o currículo escolar é "o que eles ou elas devem saber?": qual conhecimento ou saber é considerado importante ou válido ou essencial para merecer ser considerado parte do currículo da escola? A resposta a essas questóes exige que se leve em conta o projeto de sociedade em andamento, alerta Silva:

Qual é o tipo de ser humano desejável para um determinado tipo de sociedade? Será a pessoa racional e ilustrada do ideal humanista da educação? Será a pessoa otimizadora e competitiva dos atuais modelos neoliberais de educação? Será a pessoa ajustada aos ideais de cidadania do moderno estado-nação? Será a pessoa desconfiada e crítica dos arranjos sociais existentes preconizadas nas teorias educacionais críticas? (2005, p. 15). 
Tais questóes inscrevem o currículo num espaço de disputa de poder, Disputa por hegemonia. O deslocamento do conhecimento para as questóes sociais e culturais emergentes pode ser interpretado como um confronto entre teorias tradicionais e pós estruturalistas. Para as primeiras importam os conhecimentos e os saberes dominantes. Estes estão dados e o problema passa a ser "como" ou qual a melhor forma de transmiti-lo. Enquanto para as teorias pós-estruturalistas a questão é "por que este conhecimento e não outro?", quais interesses fazem com que esse conhecimento e não outro esteja no currículo? (Silva, 2005, p. 15).

\subsection{A escola, o currículo escolar e respectivos responsáveis na Constituição Federal do Brasil (1988) e na LDB n ${ }^{\circ}$ 9394/1996}

Neste ponto do percurso a proposta é observar alguns documentos normativos da legislação brasileira, com objetivo de ver algumas marcas indicativas do deslocamento da lógica que preside o currículo escolar: do currículo específico (conhecimento) para o currículo que incorpora as diferentes questóes sociais e culturais. A Constituição Federal (CF) de 1988 prevê a "fixação de conteúdos mínimos para o ensino fundamental, de maneira a assegurar formação básica comum e respeito aos valores culturais e artísticos, nacionais e regionais" (artigo 210).

Quadro 3. Entes responsáveis pela educação no Brasil.

\begin{tabular}{|c|c|}
\hline Artigo 227 da Constituição Federal & Artigo $2^{\circ}$ da LDB $9394 / 1996$ \\
\hline $\begin{array}{l}\text { É dever da família, da sociedade e do Esta- } \\
\text { do assegurar à criança, ao adolescente e ao } \\
\text { jovem, com absoluta prioridade, o direito } \\
\text { à vida, à saúde, à alimentação, à educação, } \\
\text { ao lazer, à profissionalizaçâo, à cultura, à } \\
\text { dignidade, ao respeito, à liberdade e à con- } \\
\text { vivência familiar e comunitária, além de } \\
\text { colocá-los a salvo de toda forma de negli- } \\
\text { gência, discriminação, exploração, violên- } \\
\text { cia, crueldade e opressão. (grifo meu). }\end{array}$ & $\begin{array}{l}\text { Art. } 2^{\circ} \text { A educaçáo, dever da família e do } \\
\text { Estado, inspirada nos princípios de liberda- } \\
\text { de e nos ideais de solidariedade humana, } \\
\text { tem por finalidade o pleno desenvolvimen- } \\
\text { to do educando, seu preparo para o exercí- } \\
\text { cio da cidadania e sua qualificaçáo para o } \\
\text { trabalho. (grifo meu). }\end{array}$ \\
\hline
\end{tabular}

Fontes: Constituição Federal (1998); Lei de Diretrizes e Bases da Educaçăo Nacional (LDB) nº 9394/ 1996.

A primeira coluna do quadro 3 mostra que a CF (1988) inclui a educação entre os direitos à vida, à saúde, à alimentação, ao lazer, à profissionalização, à cultura, à dignidade, ao respeito, à liberdade e à convivência familiar e comunitária. $\mathrm{O}$ conjunto dos referidos direitos são da competência de três 
entes: a família, a sociedade e o Estado. A segunda coluna do quadro 3 mostra que a LDB n ${ }^{\circ} 9394 / 1996$ preceitua que o direito à educaçáo supóe "o pleno desenvolvimento do educando, seu preparo para o exercício da cidadania e sua qualificação para o trabalho", sendo esta da competência de dois entes: a família e o Estado. Reside aí uma diferença relevante, já que, ao tratar a especificidade do direito constitucional, o texto da LDB abdicaria de um dos entes responsáveis devidamente previsto pelo texto constitucional, qual seja, a sociedade. Desta equaçáo que subtrai um dos entes responsáveis pela educação, derivam problemas. Afinal, como adverte Nóvoa, estaria na hora de "devolver à sociedade" as devidas atribuiçôes, muda-se o eixo de certas questóes, prevalecendo: $\mathrm{O}$ que a sociedade pode dar à escola? Como a comunidade vai ajudar na missão educativa? À escola o que é da escola. À sociedade o que é da sociedade (Rodrigues, 2010).

Ao mesmo tempo também se verifica que, a despeito de a sociedade não aparecer como ente responsável pela educação no texto da LDB (1996), ela - a sociedade representada por museus, teatros - aparece amplamente presente nos novos temas adicionados ao currículo escolar, e o quadro ajuda a vislumbrar a questão.

\section{Quadro 4. Currículo escolar na LDB n ${ }^{\circ}$ 9394/1996: entre o texto original e os acréscimos.}

\section{Currículo escolar previsto no texto original (LDB $\left.n^{\circ} 9394 / 1996\right)$}

Art. 26. Os currículos da educação infantil, do ensino fundamental e do ensino médio devem ter base nacional comum, a ser complementada, em cada sistema de ensino e em cada estabelecimento escolar, por uma parte diversificada, exigida pelas características regionais e locais da sociedade, da cultura, da economia e dos educandos.

$\$ 8^{\circ} \mathrm{A}$ exibição de filmes de produção nacional constituirá componente curricular complementar integrado à proposta pedagógica da escola, sendo a sua exibição obrigatória por, no mínimo, 2 (duas) horas mensais. (Incluído pela Lei $\mathrm{n}^{\circ}$ 13.006, de 2014)

\section{Currículo escolar acrescido ao texto original}

$\$ 8^{\circ}$ A exibição de filmes de produção nacional constituirá componente curricular complementar integrado à proposta pedagógica da escola, sendo a sua exibição obrigatória por, no mínimo, 2 (duas) horas mensais. (Incluído pela Lei $\mathrm{n}^{\circ}$ 13.006, de 2014)

$\$ 9^{\circ}$ Conteúdos relativos aos direitos humanos e à prevenção de todas as formas de violência contra a criança, o adolescente e a mulher serão incluídos, como temas transversais, nos currículos de que trata o caput deste artigo, observadas as diretrizes da legislação correspondente e a produção e distribuição de material didático adequado a cada nível de ensino. (Redação dada pela Lei $n^{\circ} 14.164$, de 2021) 


\begin{tabular}{|c|c|}
\hline $\begin{array}{l}\text { Currículo escolar previsto no texto } \\
\left.\text { original (LDB n }{ }^{\circ} 9394 / 1996\right)\end{array}$ & $\begin{array}{c}\text { Currículo escolar acrescido ao texto } \\
\text { original }\end{array}$ \\
\hline $\begin{array}{l}\$ 1^{\circ} \text { Os currículos a que se refere o caput } \\
\text { devem abranger, obrigatoriamente, o estu- } \\
\text { do da língua portuguesa e da matemática, } \\
\text { o conhecimento do mundo físico e natural } \\
\text { e da realidade social e política, especial- } \\
\text { mente do Brasil. }\end{array}$ & $\begin{array}{l}\text { Art. 26-A. Nos estabelecimentos de ensino } \\
\text { fundamental e de ensino médio, públicos } \\
\text { e privados, torna-se obrigatório o estudo } \\
\text { da história e cultura afro-brasileira e indí- } \\
\text { gena. (Redação dada pela Lei } n^{\circ} 11.645 \text {, } \\
\text { de } 2008 \text { ). }\end{array}$ \\
\hline $\begin{array}{l}\$ 2^{\circ} \text { O ensino da arte, especialmente em } \\
\text { suas expressões regionais, constituirá com- } \\
\text { ponente curricular obrigatório da edu- } \\
\text { caçáo básica. } \\
\$ 4^{\circ} \mathrm{O} \text { ensino da História do Brasil levará } \\
\text { em conta as contribuições das diferentes } \\
\text { culturas e etnias para a formaçáo do povo } \\
\text { brasileiro, especialmente das matrizes indí- } \\
\text { gena, africana e europeia. } \\
\text { Especificidades da educação no campo } \\
\text { ensino de língua estrangeira a partir do }\end{array}$ & $\begin{array}{l}\$ 1^{\circ} \text { O conteúdo programático a que se } \\
\text { refere este artigo incluirá diversos aspectos } \\
\text { da história e da cultura que caracterizam } \\
\text { a formação da população brasileira, a par- } \\
\text { tir desses dois grupos étnicos, tais como o } \\
\text { estudo da história da África e dos africanos, } \\
\text { a luta dos negros e dos povos indígenas no } \\
\text { Brasil, a cultura negra e indígena brasileira e } \\
\text { o negro e o índio na formação da sociedade } \\
\text { nacional, resgatando as suas contribuiçóes } \\
\text { nas áreas social, econômica e política, per- } \\
\text { tinentes à história do Brasil. (Redaçáo dada } \\
\text { pela Lei }{ }^{\circ} 11.645 \text {, de 2008). }\end{array}$ \\
\hline & $\begin{array}{l}\$ 2^{\circ} \text { Os conteúdos referentes à história e } \\
\text { cultura afro-brasileira e dos povos indíge- } \\
\text { nas brasileiros serão ministrados no âmbito } \\
\text { de todo o currículo escolar, em especial nas } \\
\text { áreas de educação artística e de literatura } \\
\text { e história brasileiras. (Redação dada pela } \\
\text { Lei } n^{\circ} 11.645 \text {, de } 2008 \text { ). }\end{array}$ \\
\hline
\end{tabular}

Fonte: Lei de Diretrizes e Bases da Educação Nacional n 9394/1996, atualizada.

Não se está aqui a questionar a relevância nem tampouco a inserção no currículo escolar de temas como direitos humanos; prevenção à violência contra crianças, adolescentes e mulheres; cultura e história afro-brasileira e indígena. O que se está problematizando é o fato de que, ao ignorar a sociedade como ente responsável pela educação, ao lado do Estado e da família (CF, 1988), este ato da LDB se difere do texto constitucional e produz a consequência imediata de sobrecarregar da escola pela via do currículo. Evidentemente que tais temas são fundamentais na contemporaneidade, conforme se propôs tratar na seção 2. Precisam ser trabalhados, sim, mas parece imprescindível que instituiçóes da sociedade (museus, fundaçôes, institutos, postos de saúde etc.), talvez devessem ser incluídos entre os responsáveis por determinadas açôes junto 
à educação na contemporaneidade, como indicaria Nóvoa (seção 1). Incluir este ente - a sociedade - ao lado do Estado e da família, no texto da LDB, é ato que corroboraria uma premissa fulcral salvaguardada pelo texto constitucional. Parece-nos que esta é uma questão que deve ser debatida.

\section{Conclusóes}

A maioria dos estudiosos do currículo escolar reconhecem os desafios que a contemporaneidade impóe sobre a revisão e a prática dos currículos escolares, reconhecendo tanto a premência de novos temas da cena sociocultural como o desafio que estes representam para o trabalho docente e a instituição escolar. Procurou-se mostrar aqui, que em alguma medida, o caldo entornado sobre o currículo escolar na escola contemporânea advém da conjuntura na qual explodem a memória abafada de povos originários, os conflitos étnico-raciais traduzindo feridas que náo cicatrizadas, a cobrança pelo pagamento de dívidas históricas, diversidades de gênero a questionarem a repressão e reivindicarem a variedade humana, num mundo "convulsionado e comunicante" dadas às novas tecnologias de comunicação e informação e uma respectiva sociedade alucinada por informaçóes a quem se deve garantir o direito à inteligibilidade das mesmas, isto é, ao conhecimento. Neste cenário a escola é profundamente desafiada a examinar seus limites e suas possibilidades em dar respostas às demandas contemporâneas.

\section{REFERÊNCIAS BIBLIOGRÁFICAS}

Barra, V. M. L. da. (2014). Tempo e espaço na escola de tempo integral de Goiânia: traços de um projeto educacional contemporâneo. In V. M. L. da Barra (Org.), Educação: ensino, espaço e tempo na escola de tempo integral. Goiânia, GO: CEGRAF UFG.

Brasil. (1988). Constituição Federal. Recuperado de http://www.planalto.gov.br/ ccivil_03/Constituicao/Constituicao.htm

Brasil. (1996). Lei de Diretrizes e Bases da Educação Nacional. Recuperado de http://www.planalto.gov.br/ccivil_03/LEIS/L9394.htm

Dalben, A. I. L. de F. (2011). Escola para o conhecimento e para a aprendizagem ou escola para o acolhimento: são incompatíveis? In J. C. Libâneo \& M. V. T. Suanno (Orgs.), Didática e escola em uma sociedade complexa (pp. 59-74). Goiânia, GO: CEPED 
Dosse, F. (2004). O método histórico e os vestígios memoriais. In E. Morin, A religação dos saberes: o desafio do século XXI (pp. 395-407). Rio de Janeiro, RJ: Bertrand Brasil.

Garcia, R. L. \& Moreira, A. F. B. (2006). Começando uma conversa sobre currículo. In R. L. Garcia \& A. F. B. M. Moreira (Orgs.), Currículo na contemporaneidade: incertezas e desafios. Sáo Paulo, SP: Cortez Editora.

Gumbrech, H. U. (2010) Produção de presença: o que o sentido não consegue transmitir. Rio de Janeiro, RJ: Contraponto \& Editora UC Rio.

Libâneo, J. C. (2011). As políticas educacionais: ênfase nos insumos e desapreço pelos aspectos didático-pedagógicos. In J. C. Libâneo \& M. V. T. Suanno (Orgs.), Didática e escola em uma sociedade complexa (pp. 85-111). Goiânia, GO: CEPED.

Libâneo, J. C. (2020). Finalidades educativas escolares em disputa, currículo e didática. In J. C. Libâneo, A. D. F. Echar, S. V. L. Rosa \& M. V. R. Suanno (Orgs.), em defesa do direito à educaçáo escolar: Didática, currículo e políticas educacionais em debate. Goiânia, GO: Editora Espaço Acadêmico.

Libâneo, J. C., \& Silva, E. (2020). Finalidades educativas escolares e escola socialmente justa: a abordagem pedagógica da diversidade social e cultural. Revista on-line de Política e Gestão educacional, 24(1), 816-840. https:// doi.org/10.22633/rpge.v24iesp1.13783

Miranda, M. G. de. (2005). Sobre tempos e espaços da escola: do princípio do conhecimento ao princípio da socialidade. Educação \& Sociedade, 26(91), 639-651. https://doi.org/10.1590/S0101-73302005000200017

Moreira, A. F. B. (1997). Currículo, utopia e pós-modernidade. In A. F. B. Moreira (Org.), Currículo: questôes atuais. Campinas, SP: Papirus.

Novaes, B. B. (2017) A presença e materialidade da comunicação. Revista do Programa de Pós-Graduação em Comunicação e Cultura da Escola de Comunicação da UFRJ, 20(2), 359-370.

Rodrigues, C. (2010, 01 de julho). António Nóvoa fala sobre conteúdos que devem ser prioritários na escola. Nova Escola: Gestão. Recuperado de https://gestao escolar.org.br/conteudo/625/antonio-novoa-fala-sobre-conteudosque-devem-ser-prioritarios-na-escola

Paro, V., Ferreti, C., Trento, D. \& Vianna, C. P. (1988) Escola de tempo integral: desafio para o ensino público. São Paulo, SP: Cortez \& Autores Associados.

Silva, T. T. da. (2005). Documentos de identidade: uma introduçâo às teorias do currículo. Belo Horizonte, MG: Autêntica.

Souza Santos, J. B. (2003). Pela mão de Alice: o social e o político na pós-modernidade. São Paulo, SP: Cortez Editora. 